\title{
Los estatutos de las organizaciones empresariales como fuente para el conocimiento de sus tipologías documentales
}

\author{
Miguel Ángel del Prado Martínez \\ CEPYME Aragón, Zaragoza (España)
}

\section{Resumen}

Estudio de caso sobre la utilidad que ofrecen los estatutos de las organizaciones empresariales para conocer las tipologías documentales que se pueden encontrar en sus archivos. El desconocimiento de estas tipologías se presenta como uno de los principales problemas operativos en este ámbito institucional, por lo que se considera necesario analizar las distintas fuentes que aporten información sobre las mismas. Tras estudiar el contenido de los estatutos y sus posibilidades como fuente de información archivística, se expone la metodología utilizada para su análisis, y finalmente se relacionan 35 tipos documentales obtenidos del examen de 10 estatutos.

Palabras clave: Archivos. Tipologías documentales. Organizaciones empresariales. Estatutos.

\section{Abstract}

This is a case study on the possiblities that the statutes of business organizations offer for establishing the documentary tipologies that can be found in their archives. The ignorance of these typologies appears like one of the main operational problems in this institutional scope. This is the reason why the analysis of the different sources that supply information on them is considered necessary. After studying the content of the statutes and its possibilities as source of archives, the methodology used for its analysis is exposed, and finally 35 documentary types obtained from the examination of 10 statutes are listed.

Keywords: Archives. Documentary typologies. Business organizations. Statutes.

\section{Introducción: a modo de declaración de principios}

En una ponencia presentada en los VIII Encuentros Internacionales sobre Sistemas de Información y Documentación (Ibersid 2003) se puso de manifiesto el escaso, por no decir nulo, desarrollo de la archivística en el ámbito de las organizaciones

Scire. $14: 1$ (en.-jun. 2008) 125-140. ISSN 1135-3716. 
empresariales (Prado, 2004). Allí se señalaba cómo estas organizaciones no han prestado mucha atención a sus archivos y existe una ausencia generalizada tanto de departamentos específicos encargados de la gestión documental como de personal cualificado al frente de dichos archivos. Al no haber profesionales trabajando en ellos no se ha desarrollado una práctica archivística, y ni mucho menos ha habido análisis teóricos sobre la documentación producida, las funciones a desarrollar en estos archivos, la metodología a aplicar... Consecuentemente, en la actualidad carecemos de una bibliografía específica que pueda orientar las actuaciones que se han de llevar a cabo en estos archivos.

A esta situación se une el vacío legal existente en materia documental, que deja en manos de las propias organizaciones empresariales la decisión sobre qué documentación producen, cómo la organizan y cuánto tiempo la conservan, por lo que están obligadas a crear de manera autónoma y carente de asesoramiento técnico sus propios modelos de gestión documental.

Que el 80\% de las organizaciones empresariales encuestadas presenten problemas de falta de espacio para conservar la documentación y que casi un $30 \%$ tenga dificultades para controlarla y localizarla pone de manifiesto las dificultades a las que se enfrentan. Por otra parte, el hecho de que el $87 \%$ de las organizaciones reconozcan la realización de expurgos nos debe alertar de los riesgos derivados de unas destrucciones llevadas a cabo al margen de normativas y ajenas a las metodologías archivísticas.

Este negro panorama, capaz de atenazar a quien asume la responsabilidad de organizar uno de estos archivos, no debe dar lugar a actitudes derrotistas. Así, un análisis comparado nos permitirá comprobar cómo instituciones con sistemas archivísticos actualmente modélicos presentaban no hace mucho tiempo un estado de desarrollo tan incipiente como el que hoy ofrecen las organizaciones empresariales. Véase el caso de los archivos municipales, autonómicos o universitarios en la década de los ochenta o incluso de los noventa. No será, por lo tanto, descabellado servirnos de las lecciones ya aprendidas por aquellas instituciones e intentar aplicar en la medida de lo posible las mejores prácticas desarrolladas por ellas.

La creación de colectivos altamente concienciados de los problemas archivísticos a los que se enfrentaban, convencidos de la posibilidad de establecer modelos comunes de actuación en instituciones semejantes y de las ventajas que podía reportar aplicar soluciones consensuadas superadoras de las viejas recetas individualistas, marcó el punto de inflexión en el modo de trabajar en los archivos y abrió paso a la normalización de procesos y, en definitiva, al avance de una disciplina como la archivística, que, con una base eminentemente práctica, tiene un corpus teórico cada vez más sólido.

Pues bien, este es el camino que creemos se debe tomar para desarrollar la archivística en las organizaciones empresariales. Está claro que lo primero que se ne- 
cesita es la existencia de un grupo de profesionales que, trabajando en los archivos de dichas organizaciones, estén dispuestos a aportar soluciones comunes. Para ello, evidentemente es prioritario que se llegue a crear puestos de trabajo en estas instituciones. ¿Imposible? Lo mismo podía parecer hace unos años para otro tipo de archivos.

Las dificultades, podemos decir estructurales, a las que se enfrentarán estos profesionales son las ya señaladas. En cuanto a los problemas operativos, se puede destacar el absoluto desconocimiento de las tipologías documentales que conforman los archivos de las organizaciones empresariales, de manera que hoy en día es imposible encontrar siquiera una lista de las mismas. Por lo tanto, un punto de arranque puede ser intentar establecer un canon —obligatoriamente generalista— de los documentos que pueden conformar el archivo de una organización empresarial.

Contra este empeño se podrá alegar que cada organización empresarial es autónoma y tiene sus propios órganos de gobierno y administración, así como distintas normas de funcionamiento, por lo que en buena lógica la documentación producida será distinta en cada asociación. Aun siendo esto cierto, creo que por encima de las peculiaridades propias de cada organización es posible encontrar puntos comunes que nos permitan llegar a generalizaciones de aplicación a todas ellas. Una vez más podemos acudir a la comparación para ver cómo en la década de los ochenta había muchas voces críticas contra el intento de establecer un modelo de clasificación común para todos los archivos municipales, basándose en las peculiaridades de los municipios en las distintas épocas y territorios españoles. Sin embargo, los trabajos de la Mesa de Trabajo sobre Organización de Archivos Municipales demostraron la posibilidad de elaborar un cuadro de clasificación de fondos de ayuntamientos aplicable en todos los municipios españoles.

Por lo tanto, y a partir de estos presupuestos, pretendemos iniciar una línea de investigación que tiene por objeto descubrir y explotar de manera sistemática aquellas fuentes de información que permitan conocer las tipologías documentales producidas por las organizaciones empresariales.

\section{Fuentes de información para conocer las tipologías documentales de las organizaciones empresariales}

\subsection{Instrumentos de descripción}

Una primera fuente de información sobre las tipologías documentales que hay en los archivos de las organizaciones empresariales son los instrumentos de descripción existentes. Aunque en estos momentos el número y la calidad de los que están accesibles es muy limitado, no por ello los debemos descartar. Así, podemos señalar el Catálogo del Archivo y Biblioteca del Instituto de Fomento del Trabajo Nacional, realizado en 1883, y, sobre todo, el Censo-guía de archivos de España

Scire. $14: 1$ (en.-jun. 2008) 125-140. ISSN 1135-3716. 
e Iberoamérica, en el que aparecen registrados 41 archivos de organizaciones empresariales, que nos ofrecen una información genérica sobre las series documentales que los conforman.

\subsection{Las fuentes legislativas}

Navarro Bonilla (1998) comprobó que la legislación española es una excelente fuente de información para determinar los tipos documentales producidos en las empresas. Así, aunque se carezca de una regulación tan extensa y unitaria como en las administraciones públicas, lo cierto es que la documentación empresarial también está sujeta a ciertas disposiciones legales, si bien de carácter disperso y subsumidas en muchas ocasiones dentro de amplias normas jurídicas destinadas a regular aspectos empresariales genéricos. Tras un riguroso análisis de esta dispersa normativa legal, este autor pudo llegar a establecer la tipología documental de las empresas españolas.

Siguiendo estas pautas, hemos comprobado que en la legislación que rige las asociaciones empresariales (a saber, la Ley 19/1977, de 1 de abril, sobre regulación del derecho de asociación sindical; el Real Decreto 873/1977, de 22 de abril, sobre depósito de los estatutos de las organizaciones constituidas al amparo de la Ley 19/1977; y la Ley Orgánica 1/2002, de 22 de marzo, reguladora del derecho fundamental de asociación) existen referencias a tipos documentales de obligado cumplimiento y que por lo tanto deberán encontrarse en todos los archivos de estas organizaciones: actas fundacionales o de constitución (1), certificaciones de acuerdos (2), estatutos (3), modificaciones de estatutos (4), relaciones de asociados (5), libros de actas (5), inventarios de bienes (5).

Además, las organizaciones empresariales, desde el momento en que comienzan a desarrollar actividades y entablar relaciones con administraciones públicas y personas físicas o jurídicas privadas, se ven sometidas a las normas de aplicación general. Así, sus relaciones con las administraciones públicas están afectadas por el derecho administrativo, financiero, penal, procesal, del trabajo y de la seguridad social. Sus relaciones entre particulares están reguladas por el derecho civil y mercantil.

Por lo tanto, el análisis de esta legislación podrá esclarecer otros tipos documentales. Ángel Navarro Gomollón y Jaime J. Navarro Lima (2003a y 2003b) han analizado la legislación fiscal de aplicación a las organizaciones empresariales, y gracias a este trabajo hemos podido conocer los documentos fiscales que están obligadas a producir, a saber: $a$ ) declaración del Impuesto de Sociedades a partir del año 2002 para las organizaciones que superen determinados ingresos; $b$ ) solicitud de exención del Impuesto sobre el Valor Añadido; $c$ ) declaración del IVA no exento; $d$ ) declaraciones de alta y de baja en la matrícula del Impuesto de Actividades Económicas. 


\subsection{Documentos normativos internos:} los estatutos de las organizaciones empresariales

\subsubsection{Qué son los estatutos}

Los estatutos son la norma básica por la que se rige la vida societaria de una organización empresarial y en la que se regula su régimen interno de funcionamiento, sus fines y actividades y sus relaciones con el exterior. Toda asociación empresarial ha de tener obligatoriamente sus propios estatutos. La importancia normativa de estos y su carácter obligatorio en todas las organizaciones empresariales nos han llevado a analizar sus posibilidades como fuente de información archivística.

\subsubsection{Contenido}

Todos los estatutos han de tener unos contenidos mínimos que vienen exigidos por la legislación. Así, el Real Decreto 873/1977, en su artículo 3, establece que habrán de contener, al menos, los siguientes extremos:

1. Denominación de la organización, que no podrá coincidir ni inducir a confusión con otra legalmente inscrita.

2. ${ }^{\circ}$ Domicilio y ámbitos territorial y profesional, determinados para las asociaciones por el sector o rama de actuación económica, la profesión o cualquier otro concepto análogo que los trabajadores o los empresarios determinen libremente en los Estatutos.

3. ${ }^{\circ}$ Los órganos de representación, gobierno y administración.

4. ${ }^{\circ}$ El funcionamiento de la Entidad, que habrá de ajustarse en todo momento a principios democráticos.

5. ${ }^{\circ}$ Régimen electoral, que garantice el que los cargos directivos se provean mediante sufragio libre y secreto.

6. ${ }^{\circ}$ Régimen económico, de forma que se determine el carácter, procedencia, administración y destino de sus recursos, así como los medios que permitan conocer a sus miembros la situación económica de la Entidad.

7..$^{\circ}$ Los requisitos y procedimientos para la adquisición y pérdida de la condición de miembro y sistema de constancia de los asociados componentes, en garantía de los mismos.

Por su parte, la Ley Orgánica 1/2002, reguladora del derecho fundamental de asociación, señala en su artículo 7 los contenidos de los estatutos, descendiendo en algunos casos a mayores concreciones que el Real Decreto 873/1977:

1. Los Estatutos deberán contener los siguientes extremos:

a) La denominación.

b) El domicilio, así como el ámbito territorial en que haya de realizar principalmente sus actividades.

c) La duración, cuando la asociación no se constituya por tiempo indefinido.

d) Los fines y actividades de la asociación, descritos de forma precisa.

Scire. $14: 1$ (en.-jun. 2008) 125-140. ISSN 1135-3716. 
e) Los requisitos y modalidades de admisión y baja, sanción y separación de los asociados y, en su caso, las clases de estos. Podrán incluir también las consecuencias del impago de las cuotas por parte de los asociados.

f) Los derechos y obligaciones de los asociados y, en su caso, de cada una de sus distintas modalidades.

g) Los criterios que garanticen el funcionamiento democrático de la asociación.

h) Los órganos de gobierno y representación, su composición, reglas y procedimientos para la elección y sustitución de sus miembros, sus atribuciones, duración de los cargos, causas de su cese, la forma de deliberar, adoptar y ejecutar sus acuerdos y las personas o cargos con facultad para certificarlos y requisitos para que los citados órganos queden válidamente constituidos, así como la cantidad de asociados necesaria para poder convocar sesiones de los órganos de gobierno o de proponer asuntos en el orden del día.

i) El régimen de administración, contabilidad y documentación, así como la fecha de cierre del ejercicio asociativo.

j) El patrimonio inicial y los recursos económicos de los que se podrá hacer uso.

k) Causas de disolución y destino del patrimonio en tal supuesto, que no podrá desvirtuar el carácter no lucrativo de la entidad.

2. Los Estatutos también podrán contener cualesquiera otras disposiciones y condiciones lícitas que los promotores consideren convenientes, siempre que no se opongan a las leyes ni contradigan los principios configuradores de la asociación.

3. El contenido de los Estatutos no podrá ser contrario al ordenamiento jurídico.

La legislación, por lo tanto, establece los grandes enunciados que deben recoger los estatutos, para que posteriormente cada asociación, haciendo uso de su autonomía e independencia, desarrolle los contenidos, siempre que no se opongan a las leyes ni al ordenamiento jurídico y respeten las reglas del funcionamiento democrático.

\subsubsection{Utilidad como fuente de información archivística}

Teniendo en cuenta los contenidos obligatorios que deben incluir los estatutos, enseguida comprendemos que son una fuente de información archivística de primer orden, y que difícilmente se podrá llevar a buen término un proyecto de gestión documental y organización de archivos de las entidades empresariales sin un análisis en profundidad de los mismos. Y esa importancia viene determinada porque los aspectos que regulan son precisamente aquellos que hay que descubrir en el proceso central y punto de arranque de la actual metodología archivística, es decir, en la identificación.

En estos momentos ya puede resultar ocioso resaltar la relevancia y primacía de la identificación, pues, aunque su aceptación como tarea perfectamente singularizada sea relativamente reciente (en España este reconocimiento se oficializó en el año 1991 con la celebración de las Primeras Jornadas sobre Metodología para la Identificación y Valoración de Fondos Documentales de las Administraciones 
Públicas), lo cierto es que ya está plenamente consolidada, y así lo pone de manifiesto tanto la bibliografía existente como su aplicación práctica en los distintos tipos de archivos (municipales, autonómicos, universitarios...).

Dentro de la identificación podemos diferenciar dos niveles de profundidad: uno que abarcará al fondo en general y otro que descenderá a las series documentales. A la identificación de fondos parece referirse el Diccionario de terminología archivística (1995) al definirla como la fase del tratamiento archivístico consistente en la investigación y sistematización de las categorías administrativas y archivísticas en que se sustenta la estructura de un fondo. Gracias a este proceso conseguiremos un conocimiento exhaustivo de las instituciones productoras de los documentos, su estructura orgánica, sus funciones y competencias, los procedimientos administrativos que se siguen y los tipos documentales en los que se materializan, elementos imprescindibles para la delimitación de las series documentales. El resultado de la identificación será la organización del fondo y el establecimiento del cuadro de clasificación y los criterios para la ordenación de sus series documentales, sentando así las bases para su posterior descripción (La Torre y Martín-Palomino, 2000).

Pero la identificación desciende a las series documentales y a los documentos básicos que las conforman y se vincula a la valoración, lo que posibilita establecer los plazos de permanencia de las series documentales en los distintos tipos de archivos y elaborar los calendarios de transferencias, conservación o eliminación de la documentación. Si además tenemos en cuenta que ayuda a desentrañar los circuitos administrativos que sigue la documentación en su elaboración, nos daremos cuenta de que es una fase imprescindible para asegurar una correcta gestión documental, entendida como la sucesión de actuaciones que permiten la racionalización y eficacia en la producción, mantenimiento, uso y destino final de los documentos. Pues bien, los estatutos van a ser indispensables para poder llevar a cabo el primer nivel de la identificación, el correspondiente a los fondos.

La primera fase de la identificación de un fondo tiene por finalidad conocer el organismo productor de la documentación. La legislación, respetando la autonomía de las asociaciones empresariales, no les impone un modelo de organización, señalando únicamente como obligatorias la existencia de una asamblea general como órgano supremo de gobierno y de un órgano de representación (al que no da nombre) encargado de gestionar y representar los intereses de la asociación (Ley Orgánica 1/2002, art. 11). Sin embargo, sí obliga a que los estatutos especifiquen cuáles son los órganos de representación, gobierno y administración. Por lo tanto, es preciso acudir a los estatutos para conocer los órganos productores de la documentación.

Identificados los órganos productores, se procederá a identificar las funciones, tanto las genéricas de la institución, como las específicas de cada sujeto productor Scire. $14: 1$ (en.-jun. 2008) 125-140. ISSN 1135-3716. 
de la documentación. La legislación impone que los estatutos deberán contener los fines y las actividades, descritos de forma precisa, así como el funcionamiento de la entidad, especificando su régimen electoral, su régimen económico y los requisitos y procedimientos para la adquisición y pérdida de la condición de miembro. Por lo tanto, los estatutos son también una fuente necesaria para poder identificar las funciones de las organizaciones empresariales.

El análisis de estos elementos queda fuera de nuestras actuales pretensiones, por lo que nos centraremos en el tercer elemento de la identificación de los fondos: los tipos documentales. Pues bien, los estatutos también se nos presentan como una importante fuente para acercarnos a la tipología de las organizaciones empresariales.

Así, aunque la legislación solo hace una referencia genérica a la documentación de las organizaciones empresariales al señalar que los estatutos contendrán el régimen de administración, contabilidad y documentación, lo cierto es que en los estatutos se encuentran continuas referencias a tipos documentales de obligado cumplimiento.

La metodología de trabajo que hemos seguido para analizar las posibilidades que nos ofrecen los estatutos como fuente para conocer las tipologías documentales ha sido la que exponemos a continuación.

En primer lugar hemos seleccionado una muestra representativa, formada por 10 organizaciones empresariales de distinto ámbito territorial (provincial, autonómico y nacional), sectorial y tipológico (asociaciones, federaciones y confederaciones) (tabla I).

Tras analizar los estatutos de cada una de estas organizaciones en busca de los tipos documentales que en ellos aparecen referenciados, hemos elaborado una ficha por cada tipo documental hallado (véase anexo).

\begin{tabular}{|l|}
\hline $\begin{array}{l}\text { Asociación de Comerciantes de Accesorios y Repuestos de Automoción de la Provincia de Zaragoza } \\
\text { (ACARAZ) }\end{array}$ \\
\hline Asociación de Talleres de Reparación de Vehículos de Zaragoza (ATARVEZ) \\
\hline Federación de Empresarios del Metal de Zaragoza (FEMZ) \\
\hline Confederación Española de Organizaciones Empresariales del Metal (CONFEMETAL) \\
\hline Confederación de Empresarios de Zaragoza (CEZ) \\
\hline Confederación Regional de Empresarios de Aragón (CREA) \\
\hline Confederación Española de Organizaciones Empresariales (CEOE) \\
\hline Confederación de la Pequeña y Mediana Empresa de Zaragoza (CEPYME Zaragoza) \\
\hline Confederación de la Pequeña y Mediana Empresa Aragonesa (CEPYME Aragón) \\
\hline Confederación de la Pequeña y Mediana Empresa (CEPYME) \\
\hline
\end{tabular}

Tabla I. Organizaciones empresariales seleccionadas. 
A partir de esas fichas de tipos documentales, procedimos al análisis de las variables aparecidas, para lo que construimos, en una fase intermedia, una tabla con dos entradas: una para los tipos documentales y otra para las organizaciones empresariales. De esta manera hemos obtenido una relación de 35 tipos documentales citados en los estatutos analizados. Como media, en cada estatuto se mencionan 22. Hay 8 tipos que aparecen en todos los estatutos y 19 que lo hacen al menos en el $50 \%$ de los casos (tabla II).

\begin{tabular}{|c|c|}
\hline Actas de reuniones de los órganos de gobierno & $100 \%$ \\
\hline Convocatorias a reuniones de los órganos de gobierno & $100 \%$ \\
\hline Cuotas de asociados & $100 \%$ \\
\hline Estatutos y modificaciones & $100 \%$ \\
\hline Expedientes de expulsión / expulsiones & $100 \%$ \\
\hline Presupuestos ordinarios de ingresos y gastos & $100 \%$ \\
\hline Solicitudes de baja / renuncias & $100 \%$ \\
\hline Solicitudes de ingreso & $100 \%$ \\
\hline Liquidaciones de cuentas & $90 \%$ \\
\hline Memorias anuales de actividades & $80 \%$ \\
\hline Registros de miembros / libros de altas y bajas / censos de asociados & $80 \%$ \\
\hline Programas y planes de actuación & $70 \%$ \\
\hline Reglamentos de régimen interior & $70 \%$ \\
\hline Contratos & $60 \%$ \\
\hline Expedientes de elecciones & $60 \%$ \\
\hline Certificados & $50 \%$ \\
\hline Delegaciones / representaciones en las reuniones de los órganos de gobierno & $50 \%$ \\
\hline Libros de actas de las reuniones de los órganos de gobierno & $50 \%$ \\
\hline Poderes & $50 \%$ \\
\hline Informes de actuación & $30 \%$ \\
\hline Libros oficiales de contabilidad & $30 \%$ \\
\hline Solicitudes de reingreso & $30 \%$ \\
\hline Presupuestos extraordinarios & $20 \%$ \\
\hline Auditorías de cuentas & $10 \%$ \\
\hline Circulares & $10 \%$ \\
\hline Designaciones de representantes en los órganos de gobierno & $10 \%$ \\
\hline Expedientes disciplinarios & $10 \%$ \\
\hline Informes y dictámenes & $10 \%$ \\
\hline Inventarios de bienes y derechos de propiedad & $10 \%$ \\
\hline Memorias, balances y cuentas de cada ejercicio & $10 \%$ \\
\hline Órdenes de pagos y libramientos & $10 \%$ \\
\hline
\end{tabular}

Scire. $14: 1$ (en.-jun. 2008) 125-140. ISSN 1135-3716. 


\begin{tabular}{|l|c|}
\hline Registro de vocales en los órganos de gobierno & $10 \%$ \\
\hline Reglamentos electorales & $10 \%$ \\
\hline Solicitudes de reuniones extraordinarias de la Asamblea General & $10 \%$ \\
\hline Solicitudes de veto & $10 \%$ \\
\hline
\end{tabular}

Tabla II. Tipos documentales referenciados

ordenados según su porcentaje de aparición en los estatutos analizados.

\section{Conclusiones}

Los estatutos son una fuente fundamental para llegar a conocer la tipología documental de las organizaciones empresariales. El profesional que se enfrente a la tarea de organizar uno de estos archivos no deberá obviar su análisis, pues, entre otras informaciones, le van a indicar qué documentos han de encontrarse obligatoriamente en el archivo.

El análisis sistemático de los estatutos no solo nos permitirá obtener una relación creciente de las tipologías que es posible hallar en los archivos de las organizaciones empresariales, sino que, además, atendiendo al porcentaje de ocasiones en que aparecen referenciados, se podrá obtener el canon de los documentos que conforman el archivo de una organización empresarial. A este canon habrá que añadir los tipos que la legislación tanto específica como general obliga a elaborar a las organizaciones empresariales.

El análisis de otras series documentales altamente informativas, como los reglamentos de régimen interior, las normas electorales, las actas de los órganos de gobierno o las memorias de actividades, así como los instrumentos de descripción existentes en los archivos de las organizaciones empresariales, vendrán a complementar la información obtenida.

\section{Notas}

(1) El Real Decreto 873/1977, artículo 1, establece:

Los estatutos y el acta de constitución de una asociación serán presentados por triplicado ejemplar, y esta última suscrita por sus otorgantes o, en su defecto, por los promotores y directivos, con expresión de los datos personales necesarios para su identificación.

Más explicita resulta la Ley Orgánica 1/2002 en los artículos 5 y 6:

Las asociaciones se constituyen mediante acuerdo de tres o más personas físicas o jurídicas legalmente constituidas [...]. El acuerdo de constitución, que incluirá la aprobación de los Estatutos, habrá de formalizarse mediante acta fundacional, en documento público o privado. Con el otorgamiento del acta adquirirá la asociación su personalidad jurídica y la plena capacidad de obrar, sin perjuicio de la necesidad de su inscripción a los efectos del artículo 10. El acta fundacional ha de contener:

Scire. $14: 1$ (en.-jun. 2008) 125-140. ISSN 1135-3716. 
a) El nombre y apellidos de los promotores de la asociación si son personas físicas, la denominación o razón social si son personas jurídicas, y, en ambos casos, la nacionalidad y el domicilio.

b) La voluntad de los promotores de constituir una asociación, los pactos que, en su caso, hubiesen establecido y la denominación de esta.

c) Los Estatutos aprobados que regirán el funcionamiento de la asociación, cuyo contenido se ajustará a las prescripciones del artículo siguiente.

d) Lugar y fecha de otorgamiento del acta, y firma de los promotores, o de sus representantes en el caso de personas jurídicas.

e) La designación de los integrantes de los órganos provisionales de gobierno.

(2) La Ley Orgánica 1/2002, en su artículo 6.2, señala:

$\mathrm{Al}$ acta fundacional habrá de acompañar, para el caso de personas jurídicas, una certificación del acuerdo válidamente adoptado por el órgano competente, en el que aparezca la voluntad de constituir la asociación y formar parte de ella y la designación de la persona física que la representará; y, en el caso de las personas físicas, la acreditación de su identidad. Cuando los otorgantes del acta actúen a través de representante, se acompañará a la misma la acreditación de su identidad.

(3) La Ley 19/1977, en los artículos 1 y 3, indica:

Las asociaciones mencionadas en el apartado número uno establecerán sus propios estatutos [...]. Las normas estatutarias contendrán, al menos, la denominación de la asociación, ámbito territorial y profesional, órganos de representación, gobierno y administración, recursos económicos y sistema de admisión de miembros, y regularán su funcionamiento de acuerdo con principios democráticos.

Las asociaciones constituidas al amparo de la presente Ley deberán depositar sus estatutos en la oficina pública establecida al efecto.

El depósito de los estatutos fue desarrollado por el Real Decreto 873/1977. En este se establecen las oficinas públicas en las que deben depositarse la documentación que hay que presentar (tanto en los casos de constitución como de modificación de estatutos), así como los contenidos mínimos de los estatutos. Regula la tramitación que se seguirá en el momento de su registro. Se establece la publicidad tanto del depósito de los estatutos (tablón de anuncios de la oficina pública, boletín oficial provincial y en su caso del Estado) como de los propios estatutos, que podrán ser examinados en la oficina en la que se depositaron por cualquier interesado.

Por su parte, la Ley Orgánica 1/2002 detalla por extenso el contenido que deberán tener los estatutos.

(4) El Real Decreto 873/1977, en su artículo 1.3, señala:

En los supuestos de modificación de estatutos de organizaciones ya constituidas, se acompañará la misma documentación, debiéndose reflejar en el acta el número de miembros y el de asistentes a la reunión del órgano de gobierno que adoptó el acuerdo, así como el resultado de la votación alcanzada.

Por su parte, la Ley Orgánica 1/2002, en su artículo 16, establece:

1. La modificación de los Estatutos que afecte al contenido previsto en el artículo 7 requerirá acuerdo adoptado por la Asamblea General convocada específicamente con tal objeto, deberá ser objeto de inscripción en el plazo de un mes y solo producirá efectos, tanto para los asociados como para los terceros, desde que se haya procedido a su inscripción en el

Scire. $14: 1$ (en.-jun. 2008) 125-140. ISSN 1135-3716. 
Registro de Asociaciones correspondiente, rigiendo para la misma el sentido del silencio previsto en el artículo 30.1 de la presente Ley.

Las restantes modificaciones producirán efectos para los asociados desde el momento de su adopción con arreglo a los procedimientos estatutarios, mientras que para los terceros será necesaria, además, la inscripción en el Registro correspondiente.

2. La inscripción de las modificaciones estatutarias se sujetará a los mismos requisitos que la inscripción de los Estatutos.

(5) El artículo 14 de la Ley 1/2002 establece una serie de obligaciones documentales, a saber:

Las asociaciones han de disponer de una relación actualizada de sus asociados.

Las asociaciones han de recoger en un libro las actas de las reuniones de sus órganos de gobierno y representación.

Las asociaciones han de llevar una contabilidad que permita obtener la imagen fiel del patrimonio, del resultado y de la situación financiera de la entidad, así como las actividades realizadas [...]. Deberán llevar su contabilidad conforme a las normas específicas que les resulten de aplicación [...]. Las cuentas de la asociación se aprobarán anualmente por la Asamblea General.

Las asociaciones han de efectuar un inventario de sus bienes.

\section{Referencias}

Actas de las Primeras Jornadas sobre Metodología para la Identificación y Valoración de Fondos Documentales de las Administraciones Públicas (Madrid, 1991). Madrid: s. n., 1991.

Catálogo del Archivo y Biblioteca del Instituto de Fomento del Trabajo Nacional. Barcelona, 1883.

Censo-guía de archivos de España e Iberoamérica. Madrid: Ministerio de Cultura. http://aer.mcu.es/sgae/index_censo_guia.jsp (2005-11-30).

Diccionario de terminología archivística (1995). Madrid: Subdirección General de los Archivos Estatales, 1995.

Fernández Gil, Paloma (1994). Racionalización de la gestión administrativa: identificación y tratamiento de documentos en los archivos de oficina. // AABADOM. 2 (1994) 11-19.

Gil García, Pilar (coord.) (2002). Tipología documental de universidades: propuestas de identificación y valoración. Cuenca: Universidad de Castilla - La Mancha, 2002.

Heredia Herrera, Antonia (1997). El sistema andaluz de archivos: elementos y estructuras. La identificación y la valoración, primeras funciones de la gestión documental. // Cuevas Blanco, María del Carmen; Porras Pérez, Elena; Santamaría Gallo, Abelardo (coords.). Sistemas archivísticos y tratamiento de documentos administrativos en el Estado de las Autonomías: seminario, 17 y 18 de abril de 1997, Santander. [Santander]: Consejería de Cultura y Deporte, [1997]. 39-57.

Heredia Herrera, Antonia (1999). La identificación y la valoración documentales en la gestión administrativa de las instituciones públicas. // Boletín de la ANABAD. 49:1 (1999) $19-49$.

La Torre Merino, José Luis; Martín-Palomino y Benito, Mercedes (2000). Metodología para la identificación y valoración de fondos documentales. Madrid: Ministerio de Educación, Cultura y Deporte, 2000.

Scire. $14: 1$ (en.-jun. 2008) 125-140. ISSN 1135-3716. 
López Gómez, Pedro (1998). Identificación y valoración de documentos en España a partir de 1975. // Anales de Documentación. 1 (1998) 75-97.

Mesa de Trabajo de Archivos de la Administración Local (2001). Propuesta de identificación y valoración para la selección de documentos en los archivos de la Administración Local. Logroño: Ayuntamiento, 2001.

Navarro Bonilla, Diego (1998). Los archivos de empresa: aproximación a la normativa jurídica reguladora de la producción documental en las empresas españolas. // Boletín de la ANABAD. 48 (1998) 49-75.

Navarro Gomollón, Ángel J.; Navarro Lima, Jaime J. (2003a). Aspectos contables y fiscales de las asociaciones empresariales: situación actual (primera parte). // Boletín Informativo para la Empresa. 9 (feb. 2003) 15.

Navarro Gomollón, Ángel J.; Navarro Lima, Jaime J. (2003b). Aspectos contables y fiscales de las asociaciones empresariales: situación actual (segunda parte). // Boletín Informativo para la Empresa. 10 (mar. 2003) 15.

Prado Martínez, Miguel Ángel del (2004). La archivística en el ámbito de las organizaciones empresariales: estado de la cuestión y propuestas de actuación. // Scire: Representación y Organización del Conocimiento. 10:1 (en.-jun. 2004) 185-216.

\section{Anexo: ejemplos de fichas de tipos documentales}

\begin{tabular}{|c|c|}
\hline Tipo documental & Actas de las reuniones de la Asamblea General \\
\hline Texto & $\begin{array}{l}\text { De cada reunión se levantará acta por el Secretario, en la que se re- } \\
\text { flejarán los acuerdos adoptados, así como el resumen de las opinio- } \\
\text { nes emitidas cuando no se obtenga unanimidad de criterio, o lo in- } \\
\text { teresen los asistentes. } \\
\text { Las actas podrán ser aprobadas de cualquiera de estas tres formas: } \\
\text { a) Al finalizar la sesión. } \\
\text { b) En la sesión inmediatamente posterior. } \\
\text { c) Por medio de tres interventores de actas, uno por cada provincia, } \\
\text { designados por la Asamblea General, que pertenezcan a diferen- } \\
\text { tes organizaciones afiliadas. }\end{array}$ \\
\hline Fuente & $\begin{array}{l}\text { Estatutos de la Confederación Regional de Empresarios de Aragón } \\
\text { (CREA), 1997, artículo } 18 .\end{array}$ \\
\hline
\end{tabular}

Scire. $14: 1$ (en.-jun. 2008) 125-140. ISSN 1135-3716. 


\begin{tabular}{|l|l|}
\hline Tipo documental & Convocatorias a reuniones de la Asamblea General \\
\hline Texto & $\begin{array}{l}\text { La convocatoria de la asamblea general ordinaria corresponde al pre- } \\
\text { sidente, mediante notificación personal y escrita a todas las organi- } \\
\text { zaciones miembros con quince días naturales de antelación a la fecha } \\
\text { señalada para la reunión, expresándose, si procediera, la fecha y hora } \\
\text { en que tendrá lugar la reunión en segunda convocatoria. } \\
\text { Cuando las circunstancias lo aconsejen, el presidente podrá convo- } \\
\text { car la asamblea con carácter de urgencia con un plazo de 48 horas. } \\
\text { La comunicación de la convocatoria consignará el lugar, local, fecha } \\
\text { y hora en que haya de celebrarse la asamblea y los asuntos que se } \\
\text { hayan de tratar, según el orden del día acordado por el comité eje- } \\
\text { cutivo en colaboración con la presidencia. } \\
\text { El presidente, en el apartado de ruegos y preguntas, recogerá todas } \\
\text { las propuestas que se formulen por los afiliados, mediante petición } \\
\text { escrita, cinco días antes de la fecha de la reunión. }\end{array}$ \\
\hline Fuente & $\begin{array}{l}\text { Estatutos de la Confederación de la Pequeña y Mediana Empresa de } \\
\text { Zaragoza (CEPYME Zaragoza), 1978, artículo 24. }\end{array}$ \\
\hline
\end{tabular}

\begin{tabular}{|l|l|}
\hline Tipo documental & Libros de actas del Comité Ejecutivo \\
\hline Texto & $\begin{array}{l}\text { Los acuerdos se llevarán a un libro de actas, que serán firmadas por } \\
\text { el presidente y el secretario o por quienes les sustituyan. Las certi- } \\
\text { ficaciones del libro de actas requerirán las firmas del presidente y del } \\
\text { secretario o sus sustitutos. } \\
\text { Todo asociado tendrá derecho a examinar personalmente, en el do- } \\
\text { micilio social, el libro de actas de la federación. También tendrá de- } \\
\text { recho a que se le libren testimonios de los particulares de dicho libro } \\
\text { que le afecten personalmente en forma directa o indirecta. }\end{array}$ \\
\hline Fuente & $\begin{array}{l}\text { Estatutos de la Federación de Empresarios del Metal de Zaragoza } \\
\text { (FEMZ), 1977, artículos 29.5 y 39.2. }\end{array}$ \\
\hline
\end{tabular}




\begin{tabular}{|l|l|}
\hline Tipo documental & Solicitudes de ingreso \\
\hline Texto & $\begin{array}{l}\text { El ingreso en la Confederación será voluntario. Las organizaciones } \\
\text { que lo deseen deberán solicitarlo mediante escrito al presidente de la } \\
\text { Confederación, haciendo constar de forma explícita la disposición, } \\
\text { por parte del solicitante, de acatar las normas estatutarias y el regla- } \\
\text { mento de la Confederación, así como su voluntad de cumplir los } \\
\text { acuerdos adoptados por los órganos de gobierno de la Confederación. } \\
\text { La solicitud de ingreso se acompañará con los siguientes documentos: } \\
\text { Relación de empresas afiliadas a la organización. } \\
\text { Los estatutos por los que se rigen. } \\
\text { El acuerdo del órgano competente según los estatutos, en el que cons- } \\
\text { te la decisión de afiliarse a la Confederación. } \\
\text { Un sucinto informe en el que se haga constar la entidad real y ca- } \\
\text { racterísticas peculiares de las empresas afiliadas a la organización que } \\
\text { soliciten el ingreso. }\end{array}$ \\
\hline Fuente & $\begin{array}{l}\text { Estatutos de la Confederación de la Pequeña y Mediana Empresa de } \\
\text { Zaragoza (CEPYME Zaragoza), 1978, artículos } 10 \text { y } 11 .\end{array}$ \\
\hline
\end{tabular}

\begin{tabular}{|l|l|}
\hline Tipo documental & Solicitudes de baja \\
\hline Texto & $\begin{array}{l}\text { Se perderá la condición de miembro de la asociación por voluntad } \\
\text { propia mediante escrito dirigido al presidente con una antelación mí- } \\
\text { nima de un mes con respecto a la fecha en que se desee que la baja } \\
\text { surta efecto. }\end{array}$ \\
\hline Fuente & $\begin{array}{l}\text { Estatutos de la Asociación de Talleres de Reparación de Vehículos de } \\
\text { Zaragoza (ATARVEZ), 1978, artículo 15. }\end{array}$ \\
\hline
\end{tabular}

\begin{tabular}{|l|l|}
\hline Tipo documental & Censos de asociados \\
\hline Texto & $\begin{array}{l}\text { Existirá un censo de asociados donde constarán las circunstancias per- } \\
\text { sonales de cada uno de los miembros, que estará a disposición de los } \\
\text { mismos, y de la Administración, en el domicilio de la asociación. }\end{array}$ \\
\hline Fuente & $\begin{array}{l}\text { Estatutos de la Asociación de Talleres de Reparación de Vehículos de } \\
\text { Zaragoza (ATARVEZ), 1978, artículo 12. }\end{array}$ \\
\hline
\end{tabular}




\begin{tabular}{|l|l|}
\hline Tipo documental & Presupuestos ordinarios de ingresos y gastos \\
\hline Texto & $\begin{array}{l}\text { Para cada ejercicio se formará el presupuesto ordinario de ingresos } \\
\text { y gastos, con sujeción a las normas contenidas en los presentes es- } \\
\text { tatutos y el reglamento interno de la confederación. }\end{array}$ \\
\hline Fuente & $\begin{array}{l}\text { Estatutos de la Confederación de la Pequeña y Mediana Empresa Ara- } \\
\text { gonesa (CEPYME Aragón), 1989, artículo 43. }\end{array}$ \\
\hline
\end{tabular}

\begin{tabular}{|l|l|}
\hline Tipo documental & Cuotas \\
\hline Texto & $\begin{array}{l}\text { Las cuotas que deberán pagar las organizaciones afiliadas a la Con- } \\
\text { federación serán fijadas por la Asamblea General, dentro de los cri- } \\
\text { terios que se establezcan reglamentariamente y atendiendo, al menos } \\
\text { en parte, al número de representantes que la organización afectada } \\
\text { tenga en la Asamblea General de la Confederación. }\end{array}$ \\
\hline Fuente & $\begin{array}{l}\text { Estatutos de la Confederación Española de la Pequeña y Mediana } \\
\text { Empresa (CEPYME), 1991, artículo 51. }\end{array}$ \\
\hline
\end{tabular}

